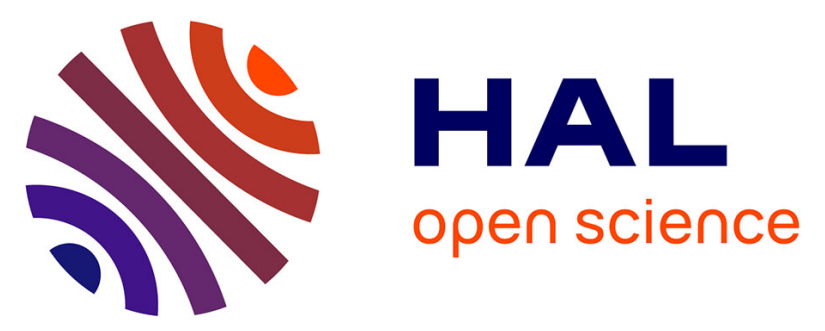

\title{
Catalyst- and Initiator-Free Radical Addition under Mild Conditions: A Macromolecular Conjugation Tool
}

Laurent Autissier, Kamel Mabrouk, Christophe Chendo, Yohann Guillaneuf, Marion Rollet, Laurence Charles, Didier Gigmes, Thomas Trimaille

\section{- To cite this version:}

Laurent Autissier, Kamel Mabrouk, Christophe Chendo, Yohann Guillaneuf, Marion Rollet, et al.. Catalyst- and Initiator-Free Radical Addition under Mild Conditions: A Macromolecular Conjugation Tool. Chemistry - A European Journal, 2018, 24 (15), pp.3699-3702. 10.1002/chem.201800035 . hal-02091848

\section{HAL Id: hal-02091848 \\ https: / hal-amu.archives-ouvertes.fr/hal-02091848}

Submitted on 12 Feb 2022

HAL is a multi-disciplinary open access archive for the deposit and dissemination of scientific research documents, whether they are published or not. The documents may come from teaching and research institutions in France or abroad, or from public or private research centers.
L'archive ouverte pluridisciplinaire HAL, est destinée au dépôt et à la diffusion de documents scientifiques de niveau recherche, publiés ou non, émanant des établissements d'enseignement et de recherche français ou étrangers, des laboratoires publics ou privés.

\section{(ㄷ)(1) $\$$}

Distributed under a Creative Commons Attribution - NonCommerciall 4.0 International 


\title{
Catalyst- and initiator-free radical addition in mild conditions and its use as a macromolecular conjugation tool
}

\author{
Laurent Autissier, ${ }^{[a]}$ Kamel Mabrouk, ${ }^{[a]}$ Christophe Chendo,${ }^{[b]}$ Yohann Guillaneuf, ${ }^{[a]}$ Marion Rollet, ${ }^{[a]}$ \\ Laurence Charles, ${ }^{[a]}$ Didier Gigmes ${ }^{*[a]}$ and Thomas Trimaille ${ }^{*[a]}$
}

\begin{abstract}
A catalyst/initiator-free radical addition reaction performed in mild conditions (water, $30^{\circ} \mathrm{C}$ ) with high yields is reported for the first time. This reaction implies simple $\mathrm{pH}$-mediated alkoxyamine dissociation followed by addition onto olefinic substrate. The versatility and relevance of this selective reaction for macromolecular conjugation and engineering is shown through synthesis of block copolymers, as well as hydrogels containing in situ loaded protein which could retain biological activity, whereas standard thermal radical conditions lead to complete protein inactivation.
\end{abstract}

In past decades radical-based addition reactions regularly enabled breakthroughs in organic chemistry and materials science. In early 90's, addition reactions involving alkyl halides, alkoxyamines or dithioester compounds onto alkenes have particularly been at the heart of the controlled radical polymerization techniques, i.e. Atom transfer Radical Polymerization (ATRP), ${ }^{[1,2]} \quad$ Nitroxide Mediated Polymerization (NMP), ${ }^{[3,4]}$ Reversible Addition Fragmentation Transfer (RAFT), ${ }^{[5,6]}$ respectively, which allowed tremendous advances in polymer material engineering. More recently, due to its inherent tolerance to many functional groups, radical addition has also appeared as a potent tool for developing selective chemical coupling approaches for modification and conjugation of polymers/bio(macro)molecules, a key issue in the design of advanced polymers/materials with precise control over architecture and functionalities. ${ }^{[7,8]}$ To this regard, radical thiol-ene and thiol-yne chemistries ${ }^{[9,10]}$ have proven to potentially compete with well-established click chemistries, such as azide-alkyne coupling, ${ }^{[11,12]}$ oxime condensation ${ }^{[13]}$ or Michael additions. ${ }^{[14]}$ Valuable nitroxide based radical coupling strategies have been further developed, such as nitroxide radical coupling, ${ }^{[15]}$ carboaminoxylation reactions $^{[16,17]}$, and intermolecular radical addition of SG1 nitroxide-based alkoxyamines onto activated olefins ${ }^{[18-21]}$

\footnotetext{
[a] L. Autissier, Dr, K. Mabrouk, Dr. Y. Guillaneuf, Dr. M. Rollet, Dr. L. Charles, Dr. D. Gigmes, Dr. T. Trimaille

Aix Marseille Univ, CNRS, ICR,

13397 Marseille Cedex 20, France

E-mail : thomas.trimaille@univ-amu.fr

[b] Dr. C. Chendo

Aix Marseille Univ, CNRS, FR1739

13397 Marseille Cedex 20, France
}

Supporting information for this article is given via a link at the end of the document.
(Scheme 1), whose an asset is the innocuous character of the involved alkoxyamines and nitroxides. ${ }^{[19,22]}$

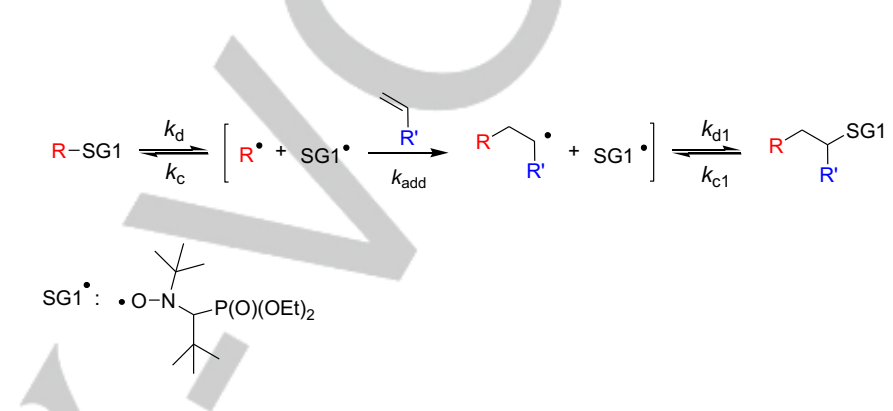

Scheme 1. General scheme of intermolecular radical addition of SG1based alkoxyamines onto activated olefins.

However, to date, all the above-mentioned radical reactions require thermal or photo activation, potentially toxic catalysts (metal-based or not) or initiators, and are generally conducted in organic solvents. Consequently there is a high need for novel radical based methodologies affording much more benign conditions and thus extended use, particularly in bio-related applications where fragile biomolecules are frequently used.

We precisely report here for the first time a radical addition at nearly room temperature and in water-friendly solvent, without any catalyst or initiator. Our approach is based on $\mathrm{pH}$ triggered alkoxyamine dissociation, allowing radical addition to occur in an "On-Off" process. We particularly exploited SG1 derived alkoxyamines bearing a pyridinyl moiety, which present a significantly increased C-ON bond dissociation rate upon protonation. ${ }^{[23,24]}$ As a result, the alkoxyamine was expected to allow radical addition process to occur with alkene functionalized (macro)molecules in mild conditions (Scheme 2). We particularly investigated the alkoxyamine 1 (4VP-SG1, Scheme 2) as pH-triggered compound, easily obtained from radical addition of commercial BlocBuilder alkoxyamine onto 4-vinylpyridine (Figs. S1-S3, ESI). This compound indeed exhibited a strongly increased $\mathrm{C}-\mathrm{ON}$ rate bond homolysis upon protonation, as determined by ${ }^{1} \mathrm{H}$ NMR (dissociation $E_{\mathrm{a}}$ values of the alkoxyamine of $105.4 \mathrm{~kJ} . \mathrm{mol}^{-1}$

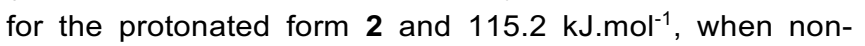
protonated, 1), consistent with earlier works. ${ }^{[23,24]}$ 

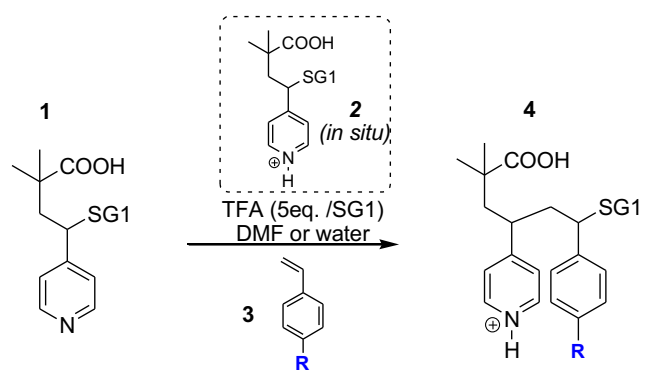

$$
\begin{array}{ll}
\text { 3a } & \mathrm{R}=\mathrm{H} \\
\text { 3b } & \mathrm{R}=\mathrm{SO}_{3} \mathrm{Na} \\
\text { 3c } & \mathrm{R}=
\end{array}
$$

4a $\quad \mathrm{R}^{\prime}=\mathrm{H}$

4b $\quad \mathrm{R}^{\prime}=\mathrm{SO}_{3} \mathrm{Na}$

4c $\mathrm{R}=\mathrm{HO}_{\mathrm{n}} \mathrm{O}^{\prime}$

Scheme 2. Intermolecular radical addition of alkoxyamine 1 onto various styrene-functionalized compounds 3a-c.

The in-situ protonation of alkoxyamine $1\left(0.16 \mathrm{~mol}^{-\mathrm{L}^{-1}}\right)$ with 5 equivalents of trifluoroacetic acid led to successful addition onto styrene (3a) at $40^{\circ} \mathrm{C}$ in dimethylformamide (DMF) (Fig 1 , chromatogram $A$ ), with a nearly total reaction yield after 72 h (Table 1, entries 1-3). The reaction yield was determined by HPLC on the crude mixtures thanks to calibration with pure isolated addition product (Fig. S12, ESI). The addition product 4a appeared in the form of three peaks showing the same expected mass (591.3) by MS (diastereomers due to presence of 3 asymetric carbons in the molecule). To confirm the impact of acidity in activation step, we performed addition in absence of TFA in the same conditions, and no addition product was observed (Fig. 1, chromatogram B). This result matches with the much higher $E_{\mathrm{a}}$ value of the non-protonated alkoxyamine 1 , and validates the proof of concept of $\mathrm{pH}$ mediated radical addition. Treatment by extraction allowed isolation of the addition product $4 \mathrm{a}$ in $61 \%$ yield and good purity. The chemical structure of addition product was further confirmed by ${ }^{1} \mathrm{H},{ }^{13} \mathrm{C}{ }^{31} \mathrm{P}$ NMR (Figs. S4-S6, ESI). From these reference conditions $\left(0.16 \mathrm{~mol} . \mathrm{L}^{-1}\right.$ of $\left.1,40^{\circ} \mathrm{C}, 72 \mathrm{~h}\right)$, decrease of temperature (to $30^{\circ} \mathrm{C}$, entry 4 , Table 1 ) or concentration (10-fold lower, entry 5 ) led to lower but still significant yield, showing the robustness of the process. This low molar concentration was tested in order to mimic the typical concentration range of (macro)alkoxyamine used in the radical addition process when macromolecules are involved. Decreasing simultaneously both temperature and concentration significantly affected the reaction yield, which however remained above $20 \%$ (entry 6 ).

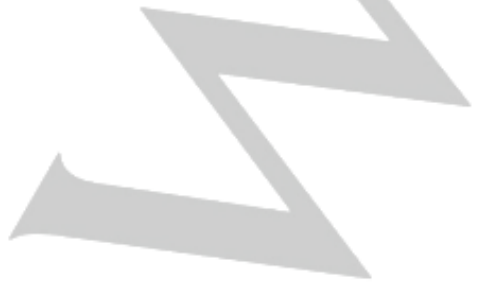

Table 1. Reaction yields for radical addition of 4VP-SG1 alkoxyamine (1) onto styrene (3a, 1.2 eq.) in DMF (5 eq. TFA) in various reaction conditions, leading to $4 a$.

\begin{tabular}{ccccc}
\hline Entry & $\begin{array}{c}{[\mathbf{1}]} \\
\left(\mathbf{m o l . L}^{-1}\right)\end{array}$ & $\begin{array}{c}\text { Temperature } \\
\left({ }^{\circ} \mathbf{C}\right)\end{array}$ & $\begin{array}{c}\text { Time } \\
(\mathbf{h})\end{array}$ & $\begin{array}{c}\text { Yield } \\
(\%)\end{array}$ \\
\hline 1 & 0.16 & 40 & 24 & 79 \\
2 & 0.16 & 40 & 48 & 90 \\
3 & 0.16 & 40 & 72 & 94 \\
4 & 0.16 & 30 & 72 & 65 \\
5 & 0.016 & 40 & 72 & 72 \\
6 & 0.016 & 30 & 72 & 24 \\
\hline
\end{tabular}

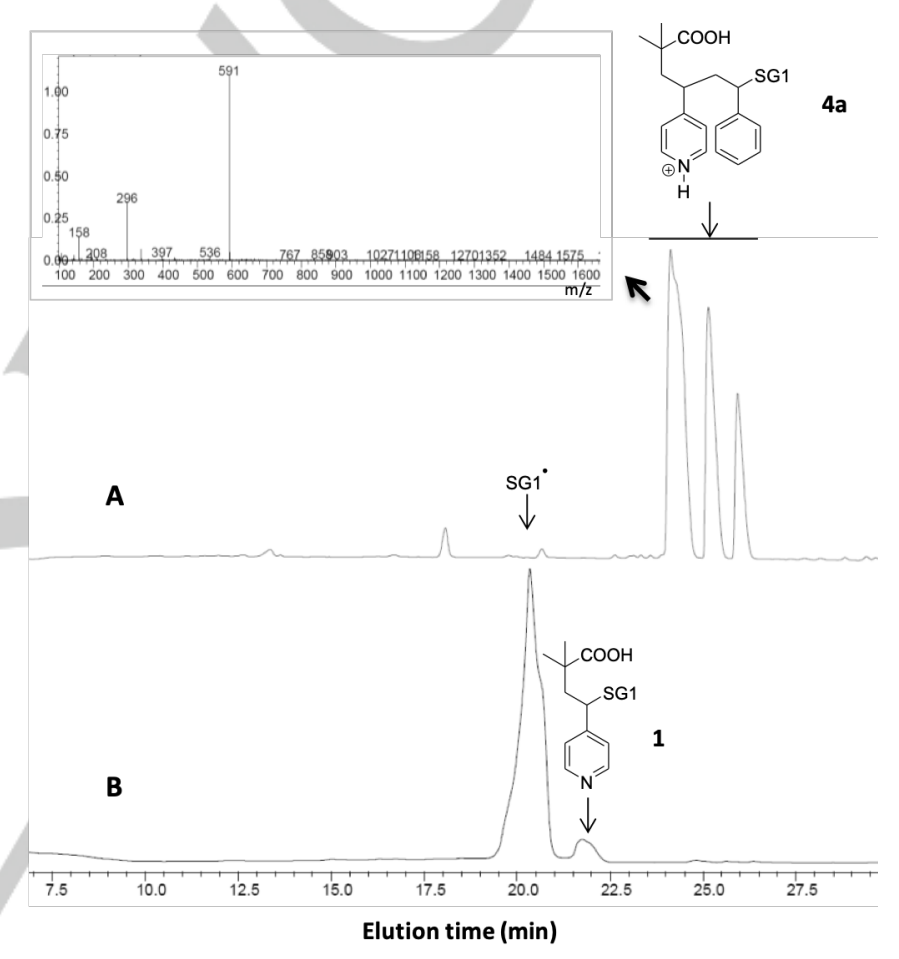

Figure 1. HPLC-UV/MS monitoring of the addition of alkoxyamine $1(0.16 \mathrm{~mol} / \mathrm{l}$, 1 eq.) on styrene (1.2 eq.) in DMF at $40^{\circ} \mathrm{C}$ during 72 hours in presence (A) or absence $(B)$ of TFA.

Interestingly, the use of protonated alkoxyamine allows to envision water as a reaction solvent. Therefore we investigated, in the same conditions, addition of alkoxyamine 1 onto sodium 4styrene sulfonate in pure water $\left(40^{\circ} \mathrm{C}, 72 \mathrm{~h}, 0.16 \mathrm{~mol} . \mathrm{L}^{-1}\right.$ of 1 , Table 2, entry $1,66 \%$ reaction yield). The addition product $\mathbf{4 b}$ appeared in the form of four peaks (Fig. S7, ESI) showing a mass corresponding to the protonated styrene sulfonate moiety $(\mathrm{M}=671.3 \mathrm{Da})$. However, the formation of two side product was observed, corresponding to starting alkoxyamine and the addition product after loss of the $t$-butyl group adjacent to the nitrogen of the SG1 aminoxy function (respectively $M=431.2 \mathrm{Da}$ and $M=615.2 \mathrm{Da}$, Fig. S7 A-B, ESI). This degradation was previously described to occur upon action of strong acids like TFA on SG1based alkoxyamines, ${ }^{[25]}$ and favoured in the presence of water as (co)solvent. Nicely, decreasing the temperature to $30^{\circ} \mathrm{C}$ allowed 
addition with better selectivity (Fig. S8, ESI), and thus higher reaction yield (Table 2, entries $2-4,89 \%$ after $72 \mathrm{~h}$ ). The addition product was isolated after purification by extraction with a yield of $85 \%$. The structure was confirmed by NMR analysis (Figs. S9S11, ESI). When a 10-fold lower concentration was used, the reaction yield remained high at $30^{\circ} \mathrm{C}$ (entry $5,80 \%$ ), and slightly decreased at $20^{\circ} \mathrm{C}$ (entry $6,72 \%$ ).

Table 2. Reaction yields for radical addition of alkoxyamine (1) onto styrene sulfonate (3b, 1.2 eq.) in water ( 5 eq. TFA) in various reaction conditions leading to $\mathbf{4 b}$.

\begin{tabular}{|c|c|c|c|c|}
\hline Entry & $\begin{array}{c}{[1]} \\
\left(\mathrm{mol}^{-L^{-1}}\right)\end{array}$ & $\begin{array}{c}\text { Temperature } \\
\left({ }^{\circ} \mathrm{C}\right)\end{array}$ & $\begin{array}{c}\text { Time } \\
\text { (h) }\end{array}$ & $\begin{array}{c}\text { Yield } \\
\text { (\%) }\end{array}$ \\
\hline 1 & 0.16 & 40 & 72 & 66 \\
\hline 2 & 0.16 & 30 & 24 & 67 \\
\hline 3 & 0.16 & 30 & 48 & 79 \\
\hline 4 & 0.16 & 30 & 72 & 89 \\
\hline 5 & 0.016 & 30 & 72 & 80 \\
\hline 6 & 0.016 & 20 & 72 & 72 \\
\hline
\end{tabular}

Our $\mathrm{pH}$ mediated radical addition was then applied to a macromolecular compound, namely a styrene-end functionalized PEO (3c). The latter was prepared from reaction of an hydroxylfunctionalized PEO $\left(M_{\mathrm{n}}=2000 \mathrm{~g} \cdot \mathrm{mol}^{-1}, \boxminus=1.05\right)$ with 4-vinylbenzyl chloride in the presence of sodium hydride $(\mathrm{NaH})$. The ${ }^{1} \mathrm{H}$ NMR analysis of the purified polymer showed a $100 \%$ styrene functionalization degree, based on peak integrals of the phenyl protons compared to methyl ether protons of the PEO (Fig. S14, ESI). Radical addition of the alkoxyamine 1 onto $3 \mathrm{c}$ was performed at $30^{\circ} \mathrm{C}$ in water for $72 \mathrm{~h}$, yielding $4 \mathrm{c}$, (alkoxyamine/polymer ratio: 5/1). This successful PEO modification process was assessed by ${ }^{1} \mathrm{H}$ NMR analysis of the purified polymer, (Fig. S16, ESI). The vinyl protons completely disappeared after radical addition, concomitantly with apparition of pyridinyl and alkoxyamine protons, with a peak integration supporting a nearly $100 \%$ functionalization degree (isolated yield $92 \%$ ). The PEO chain end functionalization was clearly confirmed by ESI-MS analysis, showing a unique distribution of molecules of molecular weight such as $M=44 n+M_{\text {end-groups }}(32<n<60)$, with $M_{\text {end-groups }}=635.4 \mathrm{Da}$, corresponding to the expected product (Fig. S15, ESI, presence of 2, 3, 4 and 5-fold charged oligomers). The prepared PEO adduct $4 \mathrm{c}$ was used as a macro-initiator for NMP of styrene in bulk at $120^{\circ}$, to achieve PEO-b-PS block copolymer. Styrene polymerization was well controlled as evidenced by the linear evolution of $M_{n}$ vs. conversion and low dispersity ( $\left.\boxminus=1.23\right)$. (Fig. S18, ESI). Block copolymer was characterized by SEC, and ${ }^{1} \mathrm{H}-\mathrm{NMR}$ after precipitation in methanol $\left(M_{\mathrm{n}}=16000 \mathrm{~g} \cdot \mathrm{mol}^{-1}\right.$ for the PS block, close to that expected). Further acute characterization by Liquid Chromatography at Limiting Conditions of Desorption (LC-LCD) indicated the single presence of block copolymer (Fig. $\mathrm{S} 21, \mathrm{ESI})$. These results show the relevance of the radical addition strategy for polymer derivatization and easy access to well-defined block architectures.
To further show the versatility of this reaction, we evaluated it for synthesis of polymer hydrogels, which are attractive materials in the field of protein delivery and tissue engineering. ${ }^{[26]}$ Up to now, the chemical strategies used for hydrogel synthesis generally were problematic regarding the remaining integrity of in situ incorporated proteins and/or cells, due to various possible factors including unreacted monomer, use of toxic coupling agents, metal catalyst, UV irradiation, or side reactions with the protein functional groups during gel formation. ${ }^{[27,28]}$ As a result, the loading approach most often used still relies on postencapsulation of the protein in hydrogels through passive diffusion, raising the problem of time consumption and low encapsulation yields. ${ }^{[29,30]}$ As shown in Fig. 2a, we prepared an hydrogel, by radical addition for $24 \mathrm{~h}$ at $30^{\circ} \mathrm{C}$ in water (or $40^{\circ} \mathrm{C}$ in DMF) between a di-functional 4VP-SG1 end-terminated PEO (previously prepared from reaction of PEG diamine with 4VPSG1, Fig. S22, ESI) and a poly(2-hydroxyethyl acrylate) (PHEA) whose $13 \%$ of the pendant hydroxyl functions were derivatized with 4-vinylbenzoic acid (styryl PHEA, Fig. S23, ESI). Formation of the gel was observed, unlike control radical addition experiment performed in absence of TFA, clearly demonstrating that gelation process proceeded through $\mathrm{pH}$-mediated radical addition (Fig. 2b). Solid state ${ }^{13} \mathrm{C}$ NMR analysis of the hydrogel after further drying confirmed nearly complete reaction yield, based on the disappearance of the vinyl carbon signals of the styrene moiety at $130 \mathrm{ppm}$ after radical addition (Fig. S24, ESI). With a view to further show the relevance of $\mathrm{pH}$ mediated radical addition towards bio-related applications, the hydrogel was synthesized in water at $30^{\circ} \mathrm{C}$ for $24 \mathrm{~h}$ in the presence of horseradish peroxidase (HRP) enzyme, a particularly fragile protein model. The same experiment was performed through classical "thermal" radical addition, namely at $80^{\circ} \mathrm{C}$ in water in absence of TFA. The integrity of the hydrogel entrapped protein was evaluated by assessing its catalytic activity for oxidation of ABTS substrate which leads to a coloured product $\left(\lambda_{\max }=420 \mathrm{~nm}\right)$ in presence of $\mathrm{H}_{2} \mathrm{O}_{2}$ in PBS buffer. While the activity of the HRP embedded in the hydrogel formed by classical radical addition at $80^{\circ} \mathrm{C}$ was completely abolished, the protein embedded in the hydrogel formed with TFA at $30^{\circ} \mathrm{C}$ was still quite active (Fig. 2c). The activity (analyzed by means of the slope of the absorbance vs. time curve) was only slightly lower for the protein in the gel than for the free protein incubated in the same conditions in absence of the polymers (TFA, $30^{\circ} \mathrm{C}, 24 \mathrm{~h}$ ) (Fig. S25, ESI). This could be attributed to the hardly accessible enzyme when entrapped in gel as compared to the free form, slowing down the product formation. Importantly, this showed that the polymers, and particularly the styrenyl and 4VP-SG1 clicking moieties, did not significantly affect the protein activity. Heating to $80^{\circ} \mathrm{C}$ for $24 \mathrm{~h}$ led to complete inactivation of the protein, either in presence or absence of the polymers, showing that these standard thermal radical addition conditions were totally inappropriate. Finally, HRP loaded hydrogels synthesized in DMF solvent, in either TFA or thermal conditions, also led to complete inactivation of the protein, showing the importance of performing the hydrogel synthesis in water friendly solvent. Thus, although acidic conditions affected to some extent protein activity 
(Fig. S25, ESI), our $\mathrm{pH}$ mediated aqueous radical addition appeared as a suitable tool for in situ protein encapsulation with retained biological function.
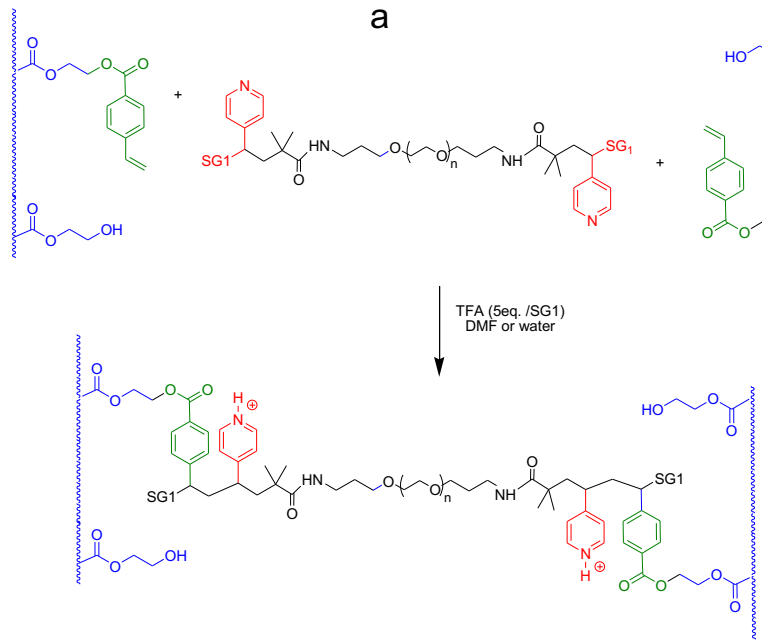

b

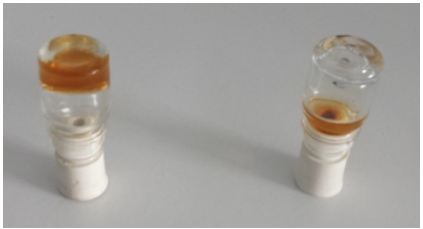

$\mathrm{C}$

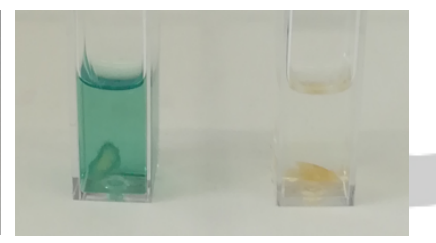

Figure 2. (a) Scheme of radical addition induced gelation between 4VP-SG1 functionalized PEO and styrene functionalized PHEA; (b) photograph of mixture after reaction in water at $30^{\circ} \mathrm{C}$ for $24 \mathrm{~h}$ in presence of TFA (left) and in absence of TFA (right); (c) activity of the in situ incorporated enzyme (assessed through formation of the coloured oxidized ABTS) after hydrogel formation at $30^{\circ} \mathrm{C}$ with TFA ( $\mathrm{pH}$-mediated radical addition, left) or $80^{\circ} \mathrm{C}$ (thermal radical addition, right) In conclusion, we here reported a radical addition in mild conditions, relying on the $\mathrm{pH}$ triggered activation of alkoxyamine based on 4-vinylpyridine. Success of the radical addition was evidenced at nearly ambient temperature, with the opportunity to run reaction in water friendly solvent. The reaction was successfully applied to polymer modification and clicking, as demonstrated by synthesis of block copolymers and hydrogels in benign conditions allowing biological activity retention of in-situ encapsulated biomolecules. To our knowledge, this is the first example of radical-based reaction performed at nearly ambient temperature without any initiator/catalyst or irradiation source.
Experimental procedures for synthesis, dissociation rate constant measurements, characterization by NMR, ESI, SEC, LC-LCD are described in Electronic Supplementary Information section.

Keywords: alkoxyamine $\cdot$ radical addition $\cdot$ water-friendly solvent $\bullet$ block copolymers $\bullet$ hydrogels.

1] M. S. Kharasch, E. V. Jensen, W. H. Urry, Science 1945, 102, 128-128.

[2] K. Matyjaszewski, J. Xia, Chem. Rev. 2001, 101, 2921-2990.

[3] C. J. Hawker, A. W. Bosman, E. Harth, Chem. Rev. 2001, 101, 36613688 .

[4] J. Nicolas, Y. Guillaneuf, C. Lefay, D. Bertin, D. Gigmes, B. Charleux, Prog. Polym. Sci. 2013, 38, 63-235.

[5] G. Moad, E. Rizzardo, S. H. Thang, Aust J. Chem 2005, 58, 379.

[6] M. Destarac, D. Charmot, X. Franck, S. Z. Zard, Macromol. Rapid Commun. 2000, 21, 1035-1039.

[7] R. K. Iha, K. L. Wooley, A. M. Nyström, D. J. Burke, M. J. Kade, C. J. Hawker, Chem. Rev. 2009, 109, 5620-5686.

[8] A. J. Inglis, C. Barner-Kowollik, Macromol. Rapid Commun. 2010, 31, 1247-1266.

[9] C. E. Hoyle, C. N. Bowman, Angew. Chem. Int. Ed. 2010, 49, 15401573.

[10] R. Pötzsch, B. C. Stahl, H. Komber, C. J. Hawker, B. I. Voit, Polym Chem. 2014, 5, 2911.

[11] H. C. Kolb, M. G. Finn, K. B. Sharpless, Angew. Chem. Int. Ed. 2001, 40, 2004-2021.

[12] M. Meldal, C. W. Tornøe, Chem. Rev. 2008, 108, 2952-3015

[13] E. W. L. Chan, M. N. Yousaf, J. Am. Chem. Soc. 2006, 128, 15542 15546.

[14] D. P. Nair, M. Podgórski, S. Chatani, T. Gong, W. Xi, C. R. Fenoli, C. N. Bowman, Chem. Mater. 2014, 26, 724-744.

[15] D. Yang, C. Feng, J. Hu, Polym. Chem. 2013, 4, 2384

[16] J.-P. Lindner, A. Studer, Chem. - Eur. J. 2011, 17, 4090-4094.

[17] C. Wetter, K. Jantos, K. Woithe, A. Studer, Org. Lett. 2003, 5, 28992902.

[18] P.-E. Dufils, N. Chagneux, D. Gigmes, T. Trimaille, S. R. A. Marque, D. Bertin, P. Tordo, Polymer 2007, 48, 5219-5225.

[19] B. Clément, T. Trimaille, O. Alluin, D. Gigmes, K. Mabrouk, F. Féron, P. Decherchi, T. Marqueste, D. Bertin, Biomacromolecules 2009, 10, 1436-1445.

[20] D. Gigmes, P.-E. Dufils, D. Glé, D. Bertin, C. Lefay, Y. Guillaneuf, Polym. Chem. 2011, 2, 1624

[21] E. Bloch, P. L. Llewellyn, T. Phan, D. Bertin, V. Hornebecq, Chem. Mater. 2009, 21, 48-55.

[22] M. Chenal, S. Mura, C. Marchal, D. Gigmes, B. Charleux, E. Fattal, P. Couvreur, J. Nicolas, Macromolecules 2010, 43, 9291-9303.

[23] D. Bertin, D. Gigmes, S. R. A. Marque, P. Tordo, Chem. Soc. Rev. 2011, 40, 2189.

[24] P. Brémond, S. R. A. Marque, Chem. Commun. 2011, 47, 4291.

[25] T. Trimaille, K. Mabrouk, V. Monnier, L. Charles, D. Bertin, D. Gigmes, Macromolecules 2010, 43, 4864-4870.

[26] T. Vermonden, R. Censi, W. E. Hennink, Chem. Rev. 2012, 112, 2853 2888.

[27] C.-C. Lin, K. S. Anseth, Pharm. Res. 2009, 26, 631-643.

[28] W. E. Hennink, C. F. van Nostrum, Adv. Drug Deliv. Rev. 2012, 64, 223-236.

[29] J. P. Schillemans, E. Verheyen, A. Barendregt, W. E. Hennink, C. F Van Nostrum, J. Controlled Release 2011, 150, 266-271.

[30] S. W. Kim, Y. H. Bae, T. Okano, Pharm. Res. 1992, 9, 283-290.

\section{Experimental Section}




\section{Entry for the Table of Contents}

Layout 1:

\section{COMMUNICATION}

We report on the first catalyst/initiator- free radical addition in mild conditions, affording versatile synthesis of block copolymers and in situ loaded protein hydrogels.

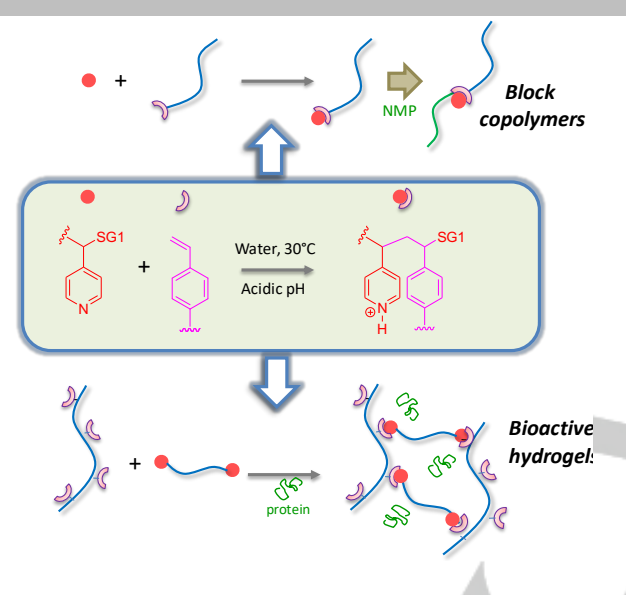

Laurent Autissier, Kamel Mabrouk, Christophe Chendo, Yohann Guillaneuf, Marion Rollet, Laurence Charles, Didier Gigmes* and Thomas Trimaille*

\section{Page No. - Page No.}

Catalyst- and initiator-free radical addition in mild conditions and its use as a macromolecular conjugation tool 